BMJ Open

Diabetes

Research

\& Care

\title{
Changes in diabetes prescription patterns following Affordable Care Act Medicaid expansion
}

\author{
Jordan Gemelas (D) , ${ }^{1,2}$ Miguel Marino, ${ }^{1,3}$ Steele Valenzuela, ${ }^{1}$ Teresa Schmidt, ${ }^{4}$ \\ Andrew Suchocki, ${ }^{5}$ Nathalie Huguet ${ }^{1}$
}

To cite: Gemelas J, Marino M, Valenzuela S, et al. Changes in diabetes prescription patterns following Affordable Care Act Medicaid expansion. BMJ Open Diab Res Care 2021;9:e002135. doi:10.1136/ bmjdrc-2021-002135

- Additional supplemental material is published online only. To view, please visit the journal online (http://dx.doi. org/10.1136/bmjdrc-2021002135).

Received 21 January 2021 Accepted 5 June 2021

\section{Check for updates}

\section{(C) Author(s) (or their} employer(s)) 2021. Re-use permitted under CC BY-NC. No commercial re-use. See rights and permissions. Published by BMJ.

${ }^{1}$ Department of Family Medicine, Oregon Health \& Science University, Portland, Oregon, USA

${ }^{2}$ School of Public Health, Oregon Health \& Science University - Portland State University, Portland, Oregon, USA

${ }^{3}$ Department of Biostatistics, Oregon Health \& Science University - Portland State University, Portland, Oregon, USA

${ }^{4}$ Research Department, OCHIN, Portland, Oregon, USA ${ }^{5}$ Clackamas County Health Clinics, Oregon City, Oregon, USA

Correspondence to Mr Jordan Gemelas; gemelas@ohsu.edu

\section{ABSTRACT}

Introduction Most patients with diabetes mellitus are prescribed medications to control their blood glucose. The implementation of the Affordable Care Act (ACA) led to improved access to healthcare for patients with diabetes. However, impact of the ACA on prescribing trends by diabetes drug category is less clear. This study aims to assess if long-acting insulin and novel agents were prescribed more frequently following the ACA in states that expanded Medicaid compared with non-expansion states.

Research design and methods In this analysis of a natural experiment, prescriptions reimbursed by Medicaid (US public insurance) for long-acting insulins, metformin, and novel agent medications (DPP4 inhibitors, sodium/glucose cotransporter 2 inhibitor antagonists, and glucagon-like peptide-1 receptor agonists) from 2012 to 2017 were obtained from public records. For each medication category, we performed difference-indifferences (DID) analysis modeling change in rate level from pre-ACA to post-ACA in Medicaid expansion states relative to Medicaid non-expansion states.

Results Expansion and non-expansion states saw a decline in both metformin and long-acting insulin prescriptions per 100 enrollees from pre-ACA to postACA. These decreases were larger in non-expansion states relative to expansion states (metformin: absolute $\mathrm{DID}=+0.33,95 \% \mathrm{Cl}=0.323$ to 0.344$)$ and long-acting insulin (absolute DID: $+0.11 ; 95 \% \mathrm{Cl}=0.098$ to 0.113 ). Novel agent prescriptions in expansion states $(+0.08$ per 100 enrollees) saw a higher absolute increase per 100 Medicaid enrollees than in non-expansion states (absolute $\mathrm{DID}=+0.08,95 \% \mathrm{Cl}=0.079$ to 0.086 ).

Conclusions There was a greater absolute increase for prescriptions of novel agents in expansion states relative to non-expansion states after accounting for number of enrollees. Reducing administrative barriers and improving the ability of providers to prescribe such newer therapies will be critical for caring for patients with diabetesparticularly in Medicaid non-expansion states.

\section{INTRODUCTION}

About 1 in 10 individuals (34 million) in the USA have diabetes. ${ }^{1}$ Most patients with diabetes are prescribed medications to control their blood glucose. ${ }^{2}$ These medications assist with long-term glycemic control and reduce the risk of diabetes-related complications

SIGNIFICANCE OF THIS STUDY
WHAT IS ALREADY KNOWN ABOUT THIS
SUBJECT?
$\Rightarrow$ Medicaid expansion following the Affordable Care
Act (ACA) dramatically increased access to medical
care among low-income populations.
$\Rightarrow$ The implementation of the ACA led to overall im-
proved access to medication among enrollees.
$\Rightarrow$ Novel agents for diabetes including sodium/glucose
cotransporter 2 inhibitors, glucagon-like peptide-1
receptor agonists, and DPP4 inhibitors are associat-
ed with numerous clinical benefits when compared
with insulin, including lower risk of hypoglycemia
and beneficial impacts on cardiovascular and renal
function.
WHAT ARE THE NEW FINDINGS?
$\Rightarrow$ Prescriptions of novel agents increased more in
Medicaid expansion states compared with non-
expansion states following implementation of the
ACA.
HOW MIGHT THESE RESULTS CHANGE THE
FOCUS OF RESEARCH OR CLINICAL PRACTICE?
$\Rightarrow$ Medicaid expansion was found to be associated with
increased access to novel diabetes medications.
$\Rightarrow$ Reducing administrative barriers and improving the
ability of providers to prescribe such newer thera-
pies will be critical for caring for patients with diabe-
tes-particularly in Medicaid non-expansion states.

like ophthalmic, renal, and peripheral nerve disease. ${ }^{3}$ Additionally, some novel agents including glucagon-like peptide-1 receptor agonists (GLP-1) and sodium/glucose cotransporter 2 inhibitors (SGLT2) have also been associated with reduced cardiovascular events among diabetes patients, may lead to some weight loss, and carry a lower risk of iatrogenic hypoglycemia. ${ }^{4-6}$ For certain patients, these novel agents are components of guideline-directed medical therapy. ${ }^{4}$ However, in the USA, the cost of diabetes medication can be a significant barrier, 
especially for low-income patients and those who lack adequate health insurance coverage. ${ }^{78}$

The US Patient Protection and Affordable Care Act (ACA) substantially improved access to health insurance and healthcare services. The ACA mandated health insurance coverage, called for the expansion of Medicaid (US publicly funded health insurance) to adults earning $\leq 138 \%$ of the federal poverty level (FPL), and provided subsidies to those making between $100 \%$ and $400 \%$ of the FPL to help purchase individual health insurance. Following the Supreme Court ruling allowing states to choose whether or not to expand Medicaid, 36 states (and the District of Columbia) expanded and 14 states did not (as of May 2020). ${ }^{9}$

Over 20 million adults gained public or private health insurance coverage. ${ }^{10}$ The ACA is associated with a decline in both the rate of uninsured patients and the rate of undiagnosed diabetes; ${ }^{11}$ an increase in diabetes diagnosis, ${ }^{12} 13$ access to preventive care and eye examinations; ${ }^{14}$ improved glycemic control; ${ }^{15}$ and a reduction in diabetes-related expenditures. ${ }^{1617}$

Some studies have demonstrated increases in prescriptions filled among patients with Medicaid following the ACA. ${ }^{1819}$ These studies showed higher rates of diabetes prescriptions in states that expanded Medicaid programs relative to states that did not expand. Medicaid expansion opened access to healthcare coverage to a different population than previously eligible. ${ }^{16} 19$ Previous studies have shown that those newly eligible for Medicaid following expansion were overall healthier and had fewer chronic conditions, but that among those with chronic health problems, their condition was more likely to be out-of-control. ${ }^{20}{ }^{21}$ It is unknown whether the change in the make-up of the Medicaid population led to differential prescription patterns for specific classes of diabetes medications. Thus, the purpose of this study was to assess if long-acting insulin and novel agent medications were prescribed more following the ACA in states that expanded Medicaid compared with non-expansion states. We specifically focus on long-acting insulin (over short-acting or intermediate-acting insulin) as it is commonly prescribed for poorly controlled diabetes and less burdensome to patients given the generally simpler dosing schemes. ${ }^{42-24}$

\section{METHODS}

A total of 26137642 prescription claims were extracted from Medicaid state drug utilization data from 2012 to 2017 obtained from the US Centers for Medicare and Medicaid Services (CMS) ${ }^{25}$ These data are publicly available and not identifiable; therefore, the research did not involve human subjects and institutional review Board approval was not necessary.

\section{Inclusion /exclusion criteria}

Medication claims were cross-referenced with National Drug Codes for all insulins, drugs containing the character string 'metformin,' and a list of novel agent prescription classes including GLP-1 agonists, DPP4 inhibitors, and SGLT2 inhibitors. ${ }^{26}$ The database includes the number of prescriptions reimbursed by Medicaid by type per US state per quarter per year. Claims with less than 11 prescriptions were suppressed by CMS for privacy purposes and were therefore excluded. However, these excluded claims comprised a small proportion of the sample and did not affect various classes differentially.

\section{Primary outcomes: diabetes medications}

Drug claims were categorized into three classes: (1) metformin, (2) long-acting insulin, and (3) novel agents (GLP-1 agonists, SGLT2 inhibitors, DPP4 inhibitors, novel agent combination therapies, and metformin combination therapies). Metformin data were included as a common first-line agent for type 2 diabetes mellitus that reflects the overall prevalence of diagnosed and treated diabetes among Medicaid enrollees. A list of the specific medications included in each class is in online supplemental appendix 1 .

\section{Primary independent variable: expansion status}

States were considered to have expanded Medicaid eligibility if they expanded as of January 2014. Expansion states included 25 states (Arizona, Arkansas, California, Colorado, Connecticut, Delaware, Hawaii, Illinois, Iowa, Kentucky, Maryland, Massachusetts, Michigan, Minnesota, Nevada, New Jersey, New Mexico, New York, North Dakota, Ohio, Oregon, Rhode Island, Vermont, Washington, and West Virginia) and the District of Columbia. A total of 19 non-expansion states included Alabama, Florida, Georgia, Idaho, Kansas, Maine, Mississippi, Missouri, Nebraska, North Carolina, Oklahoma, South Carolina, South Dakota, Tennessee, Texas, Utah, Virginia, Wisconsin, and Wyoming. During our study period, six states (New Hampshire, Pennsylvania, Alaska, Indiana, Louisiana, and Montana) expanded at a later date and were excluded from this analysis. The excluded states accounted for a minority of prescriptions $(10 \%$ of novel agents, $9 \%$ of long-acting insulin, and $8 \%$ of metformin).

\section{Statistical analyses}

First, we estimated average rates of prescriptions in each diabetes medication category (metformin, long-acting insulin, novel agents) by year and expansion status. We report unadjusted and adjusted prescription rates per 100 Medicaid enrollees by expansion and non-expansion status from 2012 to 2017. Number of enrollees per state per year served as the denominator for the rates. ${ }^{27}$ For each diabetes medication category, we performed a difference-in-difference (DID) analysis modeling change in rate level from pre-ACA to post-ACA. The unit of analyses for our models were state-years (ie, each state contributed 6 yearly observations across our study period of 2012-2017). We produced overall unadjusted and adjusted rates per 100 Medicaid enrollees by pre-ACA and post-ACA period for each expansion group and estimated 
both within-group and between-group differences. For each diabetes medication category, we performed generalized estimating equation (GEE) Poisson regression models with the following variables: an indicator denoting expansion status (state expanded Medicaid vs did not expand), an indicator for period (pre-ACA vs post-ACA), and the interaction terms between expansion status and period. In adjusted analyses, to account for differential diabetes prevalence between states and exogenous economic determinants, models were adjusted for state-level prevalence of diabetes (obtained from the Behavioral Risk Factor Surveillance System) and unemployment rates (obtained from the US Bureau of Labor Statistics).${ }^{28}{ }^{29}$ For all GEE models, we specified a Poisson distribution with a $\log \operatorname{link}$, an offset equal to $\log$ (Medicaid enrollees that year) and we utilized model-based standard errors that assumed an autoregressive correlation matrix of degree 1 to account for the autocorrelation of yearly observations within states. We used DID estimation to assess whether the change observed from pre-ACA to post-ACA was different in the expansion group relative to the non-expansion group. To provide a comprehensive view of this change over ACA implementation, we report both absolute changes in the rates within and between groups as well as relative changes in rates within and between groups. We descriptively report state-level trends to ascertain whether a single state or cluster of states disproportionately impacted overall trends. Data analyses were performed in R V.3.6.0 and V.3.6.2, and Stata V.14, and statistical significance was set at type I error of $5 \%$.

\section{RESULTS}

During the study period, there were 52492630 metformin prescriptions, 23997214 long-acting insulin prescriptions, and 4362787 novel agents prescriptions.

Figure 1 presents unadjusted expansion and nonexpansion state yearly trends in metformin, long-acting insulin, and novel agent prescription rates from 2012 to 2017. Prior to Medicaid expansion (2012-2013), prescription rates for metformin and long-acting insulin were consistently higher in expansion states compared with non-expansion states. Expansion and nonexpansion states had similar novel agent prescription rates prior to Medicaid expansion. Across all medication categories, unadjusted prescription trends were fairly parallel between expansion and non-expansion groups prior to Medicaid expansion. After Medicaid expansion, we observed differences in how prescription trends differed by expansion status, mainly starting in 2015. For metformin, non-expansion states show a similar trend after 2014 as they did prior to 2014; for expansion states, we observed a small gradual increase in prescription rates following the ACA. A similar trend was observed for longacting insulin. For novel agent medication, we observed that for both expansion and non-expansion groups, there was a steady increase in the rate of prescriptions. However, as shown in table 1, expansion states saw a higher unadjusted absolute increase in novel agent prescriptions per 100 Medicaid enrollees (expansion: +0.52 per 100 enrollees, non-expansion: +0.29 per 100 enrollees; absolute DID comparing expansion vs non-expansion states= $+0.23,95 \%$ CI $=0.228$ to 0.235 ; table 1 ).

Results from the adjusted GEE Poisson regression model are reported in table 2. In absolute terms, after covariate adjustments, both expansion and nonexpansion states saw a decline in metformin prescriptions per 100 enrollees from pre-ACA to post-ACA, with non-expansion states showing a larger decline (absolute DID estimate from pre-ACA to post-ACA expansion-nonexpansion: $-0.18-(-0.52)=0.33,95 \% \mathrm{CI}=0.323$ to 0.344$)$. In relative terms, expansion states saw a $1.1 \%$ relative decline in Metformin prescription rates from pre-ACA to post-ACA while non-expansion states saw a $6.3 \%$ decrease over the same time period (relative DID comparing relative change from pre-ACA to post-ACA between expansion and non-expansion: $0.989 / 0.937=1.056,95 \%$ $\mathrm{CI}=1.055$ to 1.057 ).

A similar trend was observed for long-acting insulin prescriptions. States that did not expand Medicaid saw a larger decline in long-acting insulin prescriptions per 100 enrollees than in expansion states resulting in an absolute DID estimate of 0.11 or 11 per 10000 enrollees ( $95 \% \mathrm{CI}=0.098$ to 0.113 ). Expansion change in prescription rates from pre-ACA to post-ACA was $-4.3 \%$, for non-expansion it was $-8.3 \%$ (relative $\mathrm{DID}=1.044$, $95 \% \mathrm{CI}=1.043$ to 1.046 )

Lastly, for novel agent prescriptions, the difference observed in the unadjusted rates is diminished. We observed an overall small increase in expansion states and no change in non-expansion states (expansion: +0.08 per 100 enrollees, non-expansion: 0 per 100 enrollees, absolute DID comparing expansion vs non-expansion= $+0.08,95 \% \mathrm{CI}=0.079$ to 0.086 ). In relative terms, expansion states saw a $7.1 \%$ relative increase in novel agent prescription rates from pre-ACA to post-ACA while nonexpansion states saw $<1 \%$ change over the same time period (relative $\mathrm{DID}=1.066,95 \% \mathrm{CI}=1.061$ to 1.071 ).

An exploratory descriptive analysis of state-level trends showed relatively similar rates across states with few influential state rates that could have overwhelmingly impacted results (online supplemental appendices 2 and $3)$.

\section{DISCUSSION}

We found a greater increase for prescriptions of novel agent medications per 100 enrollees in expansion states relative to non-expansion states. These medications have gained popularity given early data showing numerous benefits-especially for cardiovascular and renal comorbidities, and as adjunctive pharmacotherapies, ${ }^{5} 63031$ despite remaining expensive. ${ }^{32}$ This analysis suggests that Medicaid patients in expansion states were more likely to 
(a) Metformin

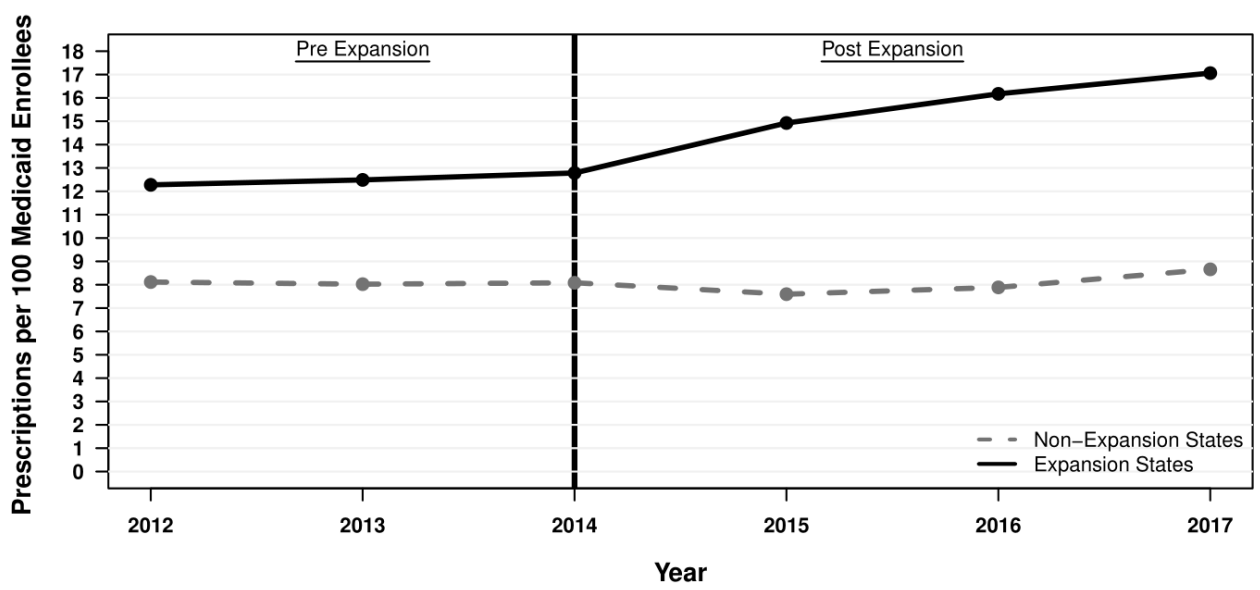

(b) Long-acting Insulin

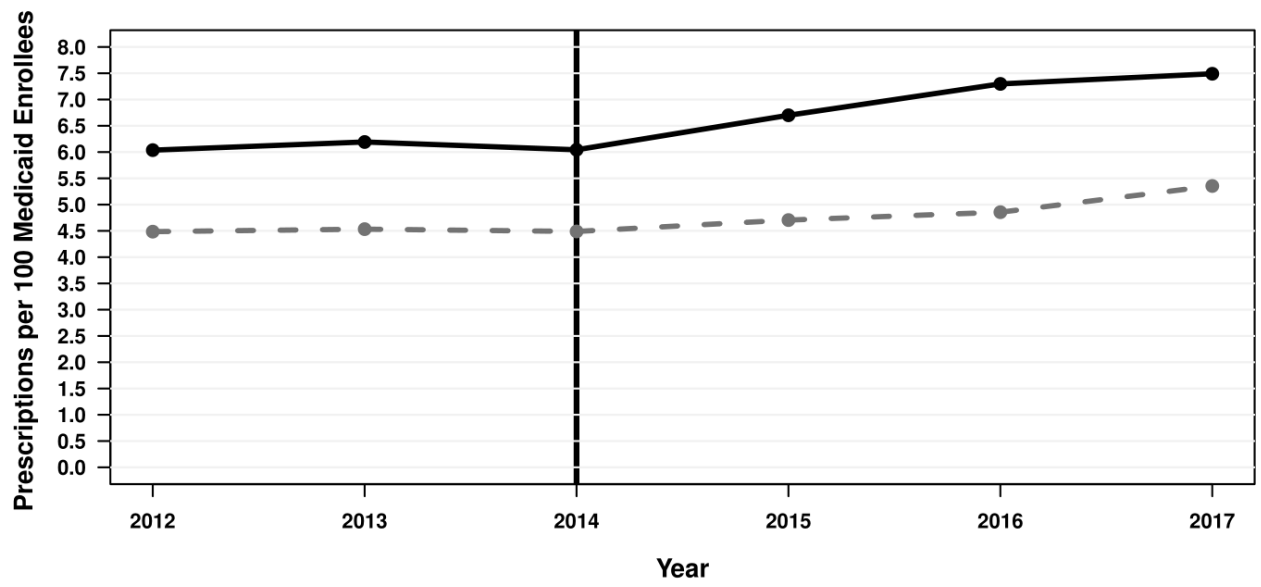

(c) Novel Agent

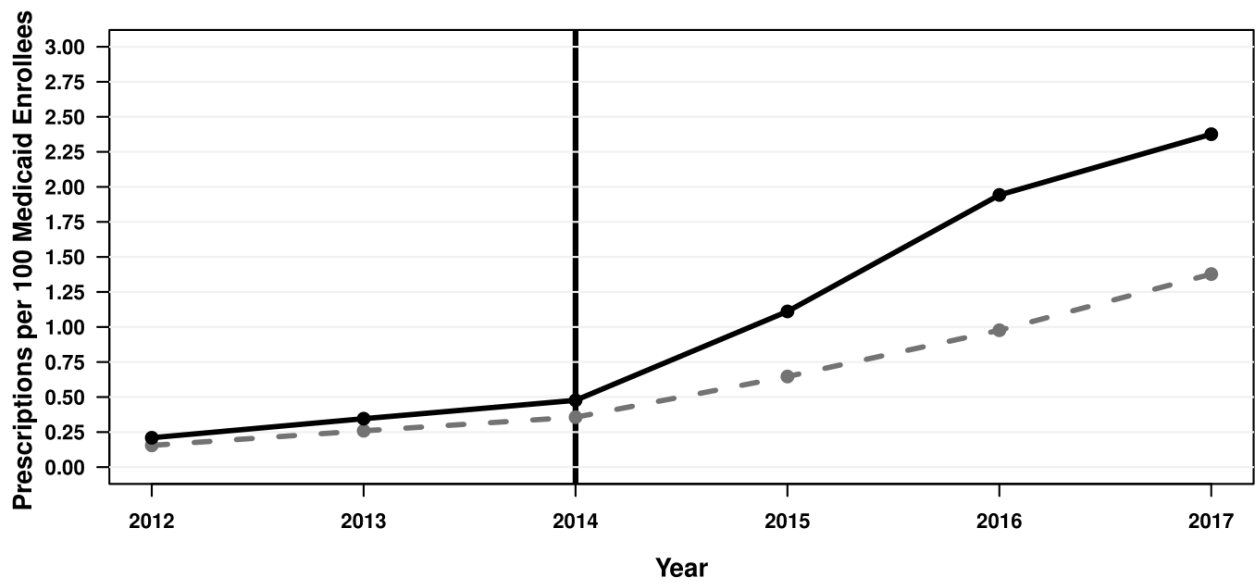

Figure 1 Unadjusted Medicaid expansion and non-expansion state yearly trends in (A) metformin, (B) long-acting insulin, and (C) novel agent prescription rates from 2012 to 2017.

be prescribed diabetes medications that are more in line with the most up-to-date standards. ${ }^{431}$

Patients who have very poor glycemic control or who have significant barriers to insulin adherence may be better candidates for these novel agents. ${ }^{22} 23$ Adherence to regimens of the novel agents may be easier for patients with a higher burden of social determinants of health because they have generally simpler dosing schemes and/or may be taken orally. ${ }^{24}$ As noted in previous studies, newly enrolled patients with chronic conditions, including diabetes, were more likely to be in a poorly managed state. ${ }^{2021}$ As these patients (who were previously unable to afford private insurance but also did not meet pre-ACA criteria for Medicaid enrollment) entered 
Table 1 Unadjusted rates in diabetes-related prescriptions pre-ACA and post-ACA Medicaid expansion between expansion groups

\begin{tabular}{|c|c|c|}
\hline Prescription & Expansion & Non-expansion \\
\hline Number of states & 25 & 19 \\
\hline \multicolumn{3}{|l|}{ Metformin } \\
\hline Pre-ACA, rate per 100 enrollees & 15.84 & 8.14 \\
\hline Post-ACA, rate per 100 enrollees & 16.67 & 8.10 \\
\hline Absolute change pre- to post-ACA & 0.83 & -0.04 \\
\hline Absolute DID (95\% Cl) & $0.87(0.866$ to 0.886$)$ & Ref. \\
\hline Relative change pre-ACA to post-ACA & $5.3 \%$ & $-0.5 \%$ \\
\hline Relative DID (95\% Cl) & 1.058 (1.056 o 1.059) & Ref. \\
\hline \multicolumn{3}{|l|}{ Long-acting insulin } \\
\hline Pre-ACA, rate per 100 enrollees & 6.69 & 4.79 \\
\hline Post-ACA, rate per 100 enrollees & 6.78 & 4.68 \\
\hline Absolute change pre-ACA to post-ACA & 0.09 & -0.11 \\
\hline Absolute DID (95\% Cl) & $0.20(0.195$ to 0.210$)$ & Ref. \\
\hline Relative change pre-ACA to post-ACA & $1.4 \%$ & $-2.3 \%$ \\
\hline Relative DID (95\% Cl) & 1.038 (1.036 to 1.039$)$ & Ref. \\
\hline \multicolumn{3}{|l|}{ Novel agents } \\
\hline Pre-ACA, rate per 100 enrollees & 1.01 & 0.53 \\
\hline Post-ACA, rate per 100 enrollees & 1.53 & 0.81 \\
\hline Absolute change pre-ACA to post-ACA & 0.52 & 0.29 \\
\hline Absolute DID (95\% Cl) & $0.23(0.228$ to 0.235$)$ & Ref. \\
\hline Relative change pre-ACA to post-ACA & $51.2 \%$ & $54.5 \%$ \\
\hline Relative DID (95\% Cl) & 0.978 (0.974 to 0.983$)$ & Ref. \\
\hline \multicolumn{3}{|c|}{$\begin{array}{l}\text { Expansion states included } 25 \text { states (Arizona, Arkansas, California, Colorado, Connecticut, Delaware, Hawaii, Illinois, lowa, Kentucky, Maryland, Massachusetts, } \\
\text { Michigan, Minnesota, Nevada, New Jersey, New Mexico, New York, North Dakota, Ohio, Oregon, Rhode Island, Vermont, Washington, and West Virginia) and } \\
\text { the District of Columbia. A total of } 19 \text { non-expansion states included Alabama, Florida, Georgia, Idaho, Kansas, Maine, Mississippi, Missouri, Nebraska, North } \\
\text { Carolina, Oklahoma, South Carolina, South Dakota, Tennessee, Texas, Utah, Virginia, Wisconsin, and Wyoming. During our study period, } 6 \text { states (New Hampshire, } \\
\text { Pennsylvania, Alaska, Indiana, Louisiana, and Montana) expanded later and were excluded from this analysis. For each diabetes medication category, we } \\
\text { performed generalized estimating equation (GEE) Poisson regression models with the following variables: an indicator denoting expansion status (state expand } \\
\text { Medicaid vs did not expand), an indicator for period (pre-ACA vs post-ACA) and the interaction terms between expansion status and period. For all GEE models, } \\
\text { we specified a Poisson distribution with a log link, an offset equal to log(Medicaid enrollees that year) and assumed an autoregressive correlation matrix of degree } 1 \\
\text { to account for the autocorrelation of yearly observations within states. } \\
\text { ACA, Affordable Care Act; DID, difference-in-differences. }\end{array}$} \\
\hline
\end{tabular}

Medicaid in expansion states, providers might have been more likely to recommend lower-maintenance options for glycemic control despite the increased administrative hurdles (eg, limited formularies requiring prior authorizations and quantity limitations). Another possible explanation for the higher prescription rates in expansion states may be the increase in diagnosed diabetes ${ }^{12} 13$ that accompanied improved primary care access following expansion. Additionally, the continued rise in insulin costs may push providers and Medicaid programs to pursue non-insulin alternatives for glycemic control when available. Appropriate coverage of novel drugs may represent equitable care for populations of patients at higher risk for poor glycemic control in the setting of competing social comorbidities. Despite the differential increase in expansion states, the novel agent medications were prescribed at a much lower overall ratio relative to long-acting insulins. Patients in non-expansion states, where a larger uninsured population exists, may face greater hurdles to accessing novel diabetes agents when compared with newly enrolled Medicaid patients in expansion states. Rapid translation of clinical evidence showing the benefits of these novel agents into reimbursement structures could reduce the number of high cost insulin claims Medicaid and other insurers must reimburse and increase access to novel agents.

\section{Limitations}

This study has some limitations. The data are Medicaid reimbursement claims; all medications that were selfpaid are excluded. No information on diabetes diagnosis, diabetes type, and combination regimens are available. Because these are drug claims, some prescriptions rarely may have been prescribed to patients without a diabetes diagnosis (eg, metformin for treatment of polycystic ovarian syndrome). A delay between 2014 expansion and measurable change in prescription claim trends may exist and could vary across states which could slightly distort the results. Of note, SGLT2 inhibitors were not made widely available until after the period of study 
Table 2 Adjusted rates in diabetes-related prescriptions pre-ACA and post-ACA Medicaid expansion between expansion groups

\begin{tabular}{|c|c|c|}
\hline Prescription & Expansion & Non-expansion \\
\hline Number of states & 25 & 19 \\
\hline \multicolumn{3}{|l|}{ Metformin } \\
\hline Pre-ACA, adjusted rate per 100 enrollees & 17.00 & 8.18 \\
\hline Post-ACA, adjusted rate per 100 enrollees & 16.82 & 7.66 \\
\hline Absolute change pre-ACA to post-ACA & -0.18 & -0.52 \\
\hline Absolute DID (95\% Cl) & 0.33 (0.323 to 0.344$)$ & Ref. \\
\hline Relative change pre-ACA to post-ACA & $-1.1 \%$ & $-6.3 \%$ \\
\hline Relative DID $(95 \% \mathrm{Cl})$ & $1.056(1.055$ to 1.057$)$ & Ref. \\
\hline \multicolumn{3}{|l|}{ Long-acting insulin } \\
\hline Pre-ACA, adjusted rate per 100 enrollees & 7.09 & 4.90 \\
\hline Post-ACA, adjusted rate per 100 enrollees & 6.79 & 4.49 \\
\hline Absolute change pre-ACA to post-ACA & -0.30 & -0.41 \\
\hline Absolute DID (95\% Cl) & $0.11(0.098$ to 0.113$)$ & Ref. \\
\hline Relative change pre-ACA to post-ACA & $-4.3 \%$ & $-8.3 \%$ \\
\hline Relative DID (95\% Cl) & 1.044 (1.043 to 1.046$)$ & Ref. \\
\hline \multicolumn{3}{|l|}{ Novel agents } \\
\hline Pre-ACA, adjusted rate per 100 enrollees & 1.20 & 0.58 \\
\hline Post-ACA, adjusted rate per 100 enrollees & 1.28 & 0.58 \\
\hline Absolute change pre-ACA to post-ACA & 0.08 & 0.00 \\
\hline Absolute DID (95\% Cl) & 0.08 (0.079 to 0.086$)$ & Ref. \\
\hline Relative change pre-ACA to post-ACA & $7.1 \%$ & $0.5 \%$ \\
\hline Relative DID (95\% Cl) & $1.066(1.061$ to 1.071$)$ & Ref. \\
\hline
\end{tabular}

Expansion states included 25 states (Arizona, Arkansas, California, Colorado, Connecticut, Delaware, Hawaii, Illinois, lowa, Kentucky, Maryland, Massachusetts, Michigan, Minnesota, Nevada, New Jersey, New Mexico, New York, North Dakota, Ohio, Oregon, Rhode Island, Vermont, Washington, and West Virginia) and the District of Columbia. A total of 19 non-expansion states included Alabama, Florida, Georgia, Idaho, Kansas, Maine, Mississippi, Missouri, Nebraska, North Carolina, Oklahoma, South Carolina, South Dakota, Tennessee, Texas, Utah, Virginia, Wisconsin, and Wyoming. During our study period, 6 states (New Hampshire, Pennsylvania, Alaska, Indiana, Louisiana, and Montana) expanded later and were excluded from this analysis. For each diabetes medication category, we performed generalized estimating equation (GEE) Poisson regression models with the following variables: an indicator denoting expansion status (state expand Medicaid vs did not expand), an indicator for period (pre-ACA vs post-ACA), the interaction terms between expansion status and period, state unemployment rate and state diabetes prevalence. For all GEE models, we specified a Poisson distribution with a log link, an offset equal to log(Medicaid enrollees that year) and assumed an autoregressive correlation matrix of degree 1 to account for the autocorrelation of yearly observations within states. Rates were adjusted for state-level unemployment rate and diabetes prevalence.

ACA, Affordable Care Act; DID, difference-in-differences.

began. Thus, some of the tabulations of pre-ACA novel agent prescriptions could have been underestimated. Additionally, national trends could have been explained by a few very populous states. However, state-level analysis in online supplemental appendices 2 and 3 shows that the overall observed trend was consistent across the vast majority of individual states. Because of the state-level aggregation, the data do not include patient demographic data or other health-related confounders; though we adjusted for state-level unemployment and diabetes prevalence. Our study cannot make direct conclusions about the newly enrolled Medicaid expansion population, but it does support findings suggested in prior studies. ${ }^{16}{ }^{19-21}$ Finally, it is uncertain whether medication claims are for new or refilled prescriptions, how many unique individuals received prescriptions, and what dosages were administered per prescription.

In conclusion, Medicaid beneficiaries in expansion states received greater access to novel agents than those residing in non-expansion states. Further research could elucidate the mechanisms behind these findings as well as ascertain whether increases in dispensing newer medication led to better diabetes outcomes. Additionally, longer follow-up may show increasing differences in novel agents trends between expansion and nonexpansion states. US health policymakers in Medicaid non-expansion states must identify strategies to increase access to novel agents for their beneficiaries.

Acknowledgements The authors wish to acknowledge Amir Meiri, MD, MPH, for his invaluable assistance with classifying the diabetes medications.

Contributors JG and NH contributed to conception, design, data management, and writing. MM and SV proposed and implemented the analysis plan and contributed to writing. TS contributed to conception, analysis, and writing. AS contributed to writing and served as the clinical advisor. All coauthors contributed to review of manuscripts.

Funding This publication was supported by Cooperative Agreement Number U18DP006116 jointly funded by the US Centers for Disease Control and Prevention and the National Institute of Diabetes and Digestive and Kidney Disease, and Patient-Centered Outcomes Research Institute.

Competing interests None declared.

Patient consent for publication Not required.

Ethics approval IRB approval was not required for the use of publicly available de-identified claims data.

Provenance and peer review Not commissioned; externally peer reviewed. 
Data availability statement Data are available in a public, open access repository. Data are publicly available at the Centers for Medicare and Medicaid Services State Drug Utilization Data website: https://www.medicaid.gov/medicaid/ prescription-drugs/state-drug-utilization-data/index.html.

Supplemental material This content has been supplied by the author(s). It has not been vetted by BMJ Publishing Group Limited (BMJ) and may not have been peer-reviewed. Any opinions or recommendations discussed are solely those of the author(s) and are not endorsed by BMJ. BMJ disclaims all liability and responsibility arising from any reliance placed on the content. Where the content includes any translated material, BMJ does not warrant the accuracy and reliability of the translations (including but not limited to local regulations, clinical guidelines, terminology, drug names and drug dosages), and is not responsible for any error and/or omissions arising from translation and adaptation or otherwise.

Open access This is an open access article distributed in accordance with the Creative Commons Attribution Non Commercial (CC BY-NC 4.0) license, which permits others to distribute, remix, adapt, build upon this work non-commercially, and license their derivative works on different terms, provided the original work is properly cited, appropriate credit is given, any changes made indicated, and the use is non-commercial. See: http://creativecommons.org/licenses/by-nc/4.0/.

ORCID iD

Jordan Gemelas http://orcid.org/0000-0002-9219-9314

\section{REFERENCES}

1 US Department of Health and Human Services. United States centers for disease control and prevention. National diabetes statistics report, 2020. Available: https://www.cdc.gov/diabetes/ pdfs/data/statistics/national-diabetes-statistics-report.pdf

2 Rodbard HW, Green AJ, Fox KM, et al. Impact of type 2 diabetes mellitus on prescription medication burden and out-of-pocket healthcare expenses. Diabetes Res Clin Pract 2010;87:360-5.

3 Diabetes Control and Complications Trial Research Group, Nathan DM, Genuth S, et al. The effect of intensive treatment of diabetes on the development and progression of long-term complications in insulin-dependent diabetes mellitus. N Engl J Med 1993;329:977-86.

4 Garber AJ, Handelsman Y, Grunberger G, et al. Consensus statement by the american association of clinical endocrinologists and american college of endocrinology on the comprehensive type 2 diabetes management algorithm - 2020 executive summary. Endocr Pract 2020;26:107-39.

5 Svanström H, Ueda P, Melbye M, et al. Use of liraglutide and risk of major cardiovascular events: a register-based cohort study in Denmark and Sweden. Lancet Diabetes Endocrinol 2019;7:106-14.

6 Pasternak B, Wintzell V, Eliasson B, et al. Use of glucagon-like peptide 1 receptor agonists and risk of serious renal events: Scandinavian cohort study. Diabetes Care 2020;43:1326-35.

7 Cefalu WT, Dawes DE, Gavlak G, et al. Insulin access and affordability Working group: conclusions and recommendations. Diabetes Care 2018;41:1299-311.

8 Grant RW, Wexler DJ, Watson AJ, et al. How doctors choose medications to treat type 2 diabetes: a national survey of specialists and academic generalists. Diabetes Care 2007;30:1448-53

9 Kaiser Family Foundation. Status of state medicaid expansion decisions: interactive map [Internet]. KFF, 2020. Available: https:// www.kff.org/medicaid/issue-brief/status-of-state-medicaidexpansion-decisions-interactive-map/

10 Tolbert J, Orgera K, Singer N. Key facts about the uninsured [Internet]. Henry J Kaiser Family Foundation, 2019. Available: http:// files.kff.org/attachment/Issue-Brief-Key-Facts-about-the-UninsuredPopulation

11 Myerson R, Romley J, Chiou T, et al. The Affordable care act and health insurance coverage among people with diagnosed and undiagnosed diabetes: data from the National health and nutrition examination survey. Diabetes Care 2019;42:e179-80.

12 Kaufman HW, Chen Z, Fonseca VA, et al. Surge in newly identified diabetes among Medicaid patients in 2014 within Medicaid expansion states under the Affordable care act. Diabetes Care 2015;38:833-7.

13 Angier H, Huguet N, Ezekiel-Herrera D, et al. New hypertension and diabetes diagnoses following the Affordable care act Medicaid expansion. Fam Med Community Health 2020;8:e000607.

14 Chen EM, Armstrong GW, Cox JT, et al. Association of the Affordable care act Medicaid expansion with dilated eye examinations among the United States population with diabetes. Ophthalmology 2020;127:920-8.

15 Marino M, Angier H, Fankhauser K, et al. Disparities in biomarkers for patients with diabetes after the Affordable care act. Med Care 2020;58 Suppl 6 Suppl 1:S31-9.

16 Casagrande SS, McEwen LN, Herman WH. Changes in health insurance coverage under the Affordable care act: a national sample of U.S. adults with diabetes, 2009 and 2016. Diabetes Care 2018;41:956-62.

17 Lindner SR, Marino M, O'Malley J, et al. Health care expenditures among adults with diabetes after oregon's medicaid expansion. Diabetes Care 2020;43:572-9.

18 Ghosh A, Simon K, Sommers BD. The Effect of Health Insurance on Prescription Drug Use Among Low-Income Adults:Evidence from Recent Medicaid Expansions. J Health Econ 2019;63:64-80.

19 Myerson R, Lu T, Tonnu-Mihara I, et al. Medicaid eligibility expansions may address gaps in access to diabetes medications. Health Aff 2018;37:1200-7.

20 Hill SC, Abdus S, Hudson JL, et al. Adults in the income range for the Affordable care act's Medicaid expansion are healthier than preACA enrollees. Health Aff 2014;33:691-9.

21 Vistnes JP, Lipton B, Miller GE. Uninsurance and insurance transitions before and after 2014: estimates for U.S., Non-elderly adults by health status, presence of chronic conditions and state medicaid expansion status. 2016 Jun. In: statistical brief (medical expenditure panel survey (US)) [Internet]; STATISTICAL BRIEF \#490. Rockville (MD: Agency for Healthcare Research and Quality (US), 2001.

22 Guerci B, Chanan N, Kaur S, et al. Lack of treatment persistence and treatment nonadherence as barriers to glycaemic control in patients with type 2 diabetes. Diabetes Ther 2019;10:437-49.

23 Giorgino F, Penfornis A, Pechtner V, et al. Adherence to antihyperglycemic medications and glucagon-like peptide 1-recepto agonists in type 2 diabetes: clinical consequences and strategies for improvement. Patient Prefer Adherence 2018;12:707-19. Volume.

24 Walker RJ, Gebregziabher M, Martin-Harris B, et al. Independent effects of socioeconomic and psychological social determinants of health on self-care and outcomes in type 2 diabetes. Gen Hosp Psychiatry 2014;36:662-8.

25 Medicaid. State drug utilization data | Medicaid, 2020. Available: https://www.medicaid.gov/medicaid/prescription-drugs/state-drugutilization-data/index.html

26 Meiri A, Zhang F, Ross-Degnan D, et al. Trends in insulin outof-pocket costs and reimbursement price among US patients with private health insurance, 2006-2017. JAMA Intern Med 2020;180:1010.

27 Kaiser Family Foundation. Current Medicaid and CHIP enrollment, 2020. Available: https://www.kff.org/state-category/medicaid-chip/ current-medicaid-chip-enrollment/

28 America's Health Rankings, United Health Foundation. Analysis of CDC, behavioral risk factor surveillance system, 2012-2017. Available: AmericasHealthRankings.org

29 U.S. Department of Labor, Bureau of Labor Statistics. Local area unemployment statistics. 2012-2017. Available: https://www.amer icashealthrankings.org/

30 American Diabetes Association. 6. glycemic targets: Standards of Medical Care in Diabetes -2020. Diabetes Care 2020;43:S66-76.

31 Davies MJ, D'Alessio DA, Fradkin J, et al. Management of hyperglycemia in type 2 diabetes, 2018. A consensus report by the American diabetes association (ADA) and the European association for the study of diabetes (EASD). Diabetes Care 2018;41:2669-701.

32 Ham SA, Nathan A, Laiteerapong N, et al. Cost-Related barriers to new diabetes Medications-A national physician survey. Diabetes 2018;67:149-LB-LB. 